\title{
REVIEW:
}

\section{Current Status of Extenders and Cryoprotectants on Fish Spermatozoa Cryopreservation}

\author{
MUCHLISIN Z.A. \\ Department of Marine Sciences, Faculty of Sciences Syiah Kuala University, Banda Aceh 23111 \\ Nanggroe Aceh Darussalam, Indonesia.
}

Received: 21 Mei 2004. Accepted: 30 September 2004.

\begin{abstract}
An important component of many studies of cryopreservation of fish spermatozoa is the type of extenders and cryoprotectants. The suitability of extenders and cryoprotectants differs from one fish to another. There are many studies have been done in cryopreservation of fish spermatozoa. However, there are few review have been done. This review reveals some aspects of cryopreservation especially the role of extender and cryoprotectant in fish sperm cryopreservation. Fish produce high viscosity of sperm and in some cases only small volume is produced. Before cryopreserved in liquid nitrogen, sperm have to dilute with extenders and for long-term cryopreservation, cryoprotectants are needed to protect the sperm cell from cold and hot shock treatments and prevent cell dehydration during pre-freezing, freezing and post thawed. The suitability of extenders and cryoprotectants differs from one fish to another. Over the last decade, studies on the cryopreservation of mammalian sperm, animal husbandry sperm and human sperm have progressed significantly but studies on fish sperm is still confined to some aquatic.
\end{abstract}

(C) 2005 Jurusan Biologi FMIPA UNS Surakarta

Key words: fish, sperm, cryopreservation, extenders, cryoprotectants.

\section{INTRODUCTION}

Cryopreservation is the method to preserve the milt. This method has been applied in fish sperm. According to Chao and Liao (2001), cryopreservation of fish sperm has been well established for many years in many finfish species. This method offers several benefits such as stock protection from being totally eliminated due to sudden diseases outbreak, natural disaster, or accidents such as oil spills. Other advantages of cryopreservation include stable supply of sperm for optimal utilization in hatchery production and laboratory experiments, easy stock transportation among hatcheries, improvement in selective breeding whereby stock can be maintained more economically and effectively, experimental material for advanced studies, such as gene transfer.

The principle of cryopreservation is to cause cell dehydration and eventually concentrate the cytosol with minimum injury so that ice crystallization in the cytosol is minimized during quenching in liquid nitrogen. Major cryoinjuries can occur in relation to freezing and thawing process during conventional cryopreservation within the temperature ranges of generalized cryopreservation procedures due to the cold shock during freezing and hot shock when the samples thawed. The cryoinjuries occur during pre-freezing and post-thawing, at the temperature range between 0 and $-40^{\circ} \mathrm{C}$. Other causes of cryoinjuries include $\mathrm{pH}$ fluctuation, ice crystal formation, osmotic pressure, and cryoprotectant toxicity (Chao and Liao, 2001).

In addition, Hammerstedt et al. (1990) reported that ice formation and changes in osmotic pressure are other major

\footnotetext{
- Alamat korespondensi:

Kampus Unsyiah Banda Aceh 23111, NAD.

Tel./fax.: +62-0651-555622

e-mail: muchlisinza@yahoo.com
}

causes of spermatozoa damage during cryopreservation, and the ability of spermatozoa plasma membrane to resist structural damage during cryopreservation may be related to the type of fatty acids in the spermatozoa plasma membrane and the strength of the bonds between membrane components.

It was postulated that fatty acids protect the cell from osmotic pressure of extenders and cryoprotectants solution and hot or cold shock during freezing and thawing further prevent cell dehydration and damages.

\section{EXTENDERS}

In terms of cryopreservation, extenders have been very well studied because cryopreservation is difficult without them. An extender is a medium to dilute sperm and to get a larger amount of diluted sperm for artificial induce breeding purposes, while a cryoprotectant is a material which added into an extended sperm dilutions to protect the sperm from cold and hot shock and cryo toxicity during cryopreservation (Muchlisin, 2004b). Some of extenders that used for cryopreservation of sperm in various fish species was listed in Table 1. (Chao, 1996).

Fish produces high viscosity of sperm and in some cases only small volume is produced. Extenders are playing a vital role in cryopreservation, it needed for sperm dilution, and generally it induced initial motility and increased fertilization of cryopreserved sperm. It is known that spermatozoa can be preserved for a day to years and their motility could be retained under low temperatures.

Ringer and physiology solutions are common practical extenders to dilute the milt, since these solutions are easy to prepare. A physiology solution contains $7.98 \mathrm{~g} / \mathrm{L} \mathrm{NaCl}$ and $0.2 \mathrm{~g} / \mathrm{L} \mathrm{NaHCO}_{3}$ (Alawi et al., 1995) while Ringer solution has $7.5 \mathrm{~g} / \mathrm{L} \mathrm{NaCl}, 0.2 \mathrm{~g} / \mathrm{L} \mathrm{KCl}, 0.20 \mathrm{~g} / \mathrm{L} \mathrm{CaCl}_{2}, 0.20$ 
$\mathrm{g} / \mathrm{L}$ and $\mathrm{NaHCO}_{3}$. Ringer solution is commonly used in freshwater fish spermatozoa. Although, modified Ringer contains $13.5 \mathrm{~g} / \mathrm{l} \mathrm{NaCl}, 0.60 \mathrm{~g} / \mathrm{KCl}, 0.25 \mathrm{~g} / \mathrm{l} \mathrm{CaCl}, 0.35 \mathrm{~g} / \mathrm{l}$ $\mathrm{MgCl}_{2}$, and $0.2 \mathrm{~g} / \mathrm{l} \mathrm{NaHCO}_{3}$ is used for marine fish spermatozoa. Ringer with milk and Ringer with honey are also reported to be suitable for tilapia (Oreochromis niloticus).and milkfish (Chanos chanos) or black porgy (Acanthopagrus schlegeli) spermatozoa respectively (Chao, 1991). In addition, Muchlisin et al. (2004a) find that Ringer solutions at dilution ratio of 1:20 resulted in higher sperm motility of bagrid catfish (Mystus nemurus).

Another extender that can be used is saline solution consisting of $75 \mathrm{mmol} / \mathrm{L} \mathrm{NaCl}, 70 \mathrm{mmol} / \mathrm{L} \mathrm{KCl}, 2 \mathrm{mmol}$ $\mathrm{CaCl}_{2}, 1 \mathrm{mmol} / \mathrm{L} \mathrm{MgSO}_{4}$, and $20 \mathrm{mmol} / \mathrm{L}$ tris $(\mathrm{pH} 8)$ which is suitable for cyprinid fish spermatozoa (Lahnsteiner et al., 2000). In addition, Kurokura-1 which contains of $128.4 \mathrm{mM}$ $\mathrm{NaCl}$. $2.7 \mathrm{mM} \mathrm{KCl}, 1.4 \mathrm{mMCaCl}_{2}, 2.4 \mathrm{mMNaHCO}_{3}$ is suitable for common carp (Cyprinus carpio) spermatozoa (Linhart, et al., 2000).

\section{CRYOPROTECTANTS}

Like extenders, cryoprotectants are also playing important role in cryopreservation particularly for long-term cryopreservation. Cryoprotectants are needed to protect the sperm cell from cold and hot shock treatments and prevent cell dehydration. Cryoprotectants provide cryoprotection to labile enzymes, for example catalase, and stabilize protein in unfrozen and aqueous solutions. They can also prevent ice formation during prefreezing, but the same levels of cryoprotectants can be lethal to unfrozen cell (Chao, 1991). However, cryoprotectants have some disadvantages in that it can induce protein denaturation at higher temperature and cause cryoprotectant toxicity in cellular systems. The toxicity of the diluents is a major limitation to successful spermatozoa cryopreservation of fishes. Some of cryoprotectants that used in cryopreservation studies was listed in Table 2. (Chao, 1996).

Since spermatozoa are very sensitive cells and are easily affected by diluents such as extenders and cryoprotectants, studies on the cryoprotectants and extenders, in terms of spermatozoa preservation are important to determine the most suitable extenders, cryoprotectants and their concentration for certain fish species. Chao (1991) also reported that very few spermatozoa survive at very low temperature without cryoprotectant due to the ice crystals that were formed.

In addition, cryoprotectants added to milt greatly extends the tolerance of spermatozoa to freezing particularly when it is done at slower rate. Here the optimal cooling rate depends on the nature and concentration of the cryoprotectant that is used. For instance, in grey mullet and black porgy, 5-15\% glycerol showed satisfactory function, while in the tilapias, $15 \%$ milk and 5\% methanol as diluentscryoprotective agent mixture gave satisfactory motility and fertility.

DMSO (dimethyl-sulfoxide) at various concentrations is generally used as a cryoprotectant for animal cells, for example $10 \%$ DMSO resulted in a high percentage of motile milkfish spermatozoa (Chao, 1991), Artic charr (Salvelinus alpinus) (Richardson et al., 2000b), and spotted sea trout (Cynoscion nebulosus) (Wayman et al., 1996), whereas $12 \%$ DMSO was found suitable for Atlantic salmon (Salmo salar L) spermatozoa (Gallant et al., 1993). However, 10\% Dimethyl-acetamide (DMA) was more effective than 10\% DMSO for cryopreservation of rainbow trout (Ochorhynchus mykiss) spermatozoa (McNiven et al., 1993; and Richardson, et al., 2000a) and African catfish (Clarias gariepinus) spermatozoa (Horvath and Urbanyi, 2000).

Also available as a cryoprotectant is glycerol which was found to be a more effective cryoprotectant than DMSO and ethylene glycol (EG) for European catfish (Silarus glanis) spermatozoa (Linhart et al., 1993). In contrast, Marian and Krasznai (1987) found DMSO better than EG in European catfish, and propylene glycol (PG) in yellowtail founder (Pleuronectes ferrugineus) (Richardson et al., 1995). Methanol also has a good protective effect for fish spermatozoa. For example, $10 \%$ methanol is suitable for cryopreservation of bitterling spermatozoa (Ohta et al., 2001), spine foot fish (Chao, 1991), bagrid catfish (Muchlisin and Muhammadar, 2002), European catfish (Ogier de Baulny et al., 1999) and African catfish (Viveiros et al., 2000), and 5\% methanol is reported to be suitable for tilapia spermatozoa (Chao, 1991).

Table 2. Cryoprotectants used in cryopreservation studies (Chao, 1996).

\begin{tabular}{lll}
\hline Acetamide & Glycerol monoacetate & Proline \\
Aline (L) & Glycine & Propylene glycol \\
Albumin & Hydroxyethyl starch & Pyridine-N-Oxide \\
Ammonium acetate & Inositol & Ribose \\
Chloroform & Lactose & Serine \\
Choline & Magnesium chloride & Sodium bromide \\
Dextrans & Magnesium sulfate & Sodium chloride \\
Diethyl glycol & Maltose & Sodium iodide \\
Dimethyl acetamide & Mannitol & Sodium nitrate \\
Dimethyl formamide & Mannose & Sodium sulfate \\
Dimethyl sulphoxide & Methanol & Sorbitol \\
Erythritol & Methyl acetamide & Sucrose \\
Ethanol & Methyl formamide & Triethylene glycol \\
Ethylene glycol & Methyl urea & Trimethylamine \\
& & acetate \\
Formamide & Phenol & Urea \\
Glucose & Pluronic polyols & Valine \\
Glycerol & Polyethylene glycol & Xylose \\
Glycerophosphate & Polyvinyl pyrrolidone & - \\
\hline
\end{tabular}

Table 1. The type of extenders used for cryopreservation of sperm in various fish species (Chao, 1996).

\begin{tabular}{|c|c|c|c|c|c|c|c|c|c|c|c|c|}
\hline \multirow{2}{*}{ Ingredient (g/L) } & $\mathrm{NaCl}$ & $\mathrm{KCl}$ & $\mathrm{CaCl}_{2}$ & $\mathrm{MgCl}_{2}$ & $\mathrm{NaHCO}_{3}$ & Taps & Caps & Glucose & Yolk & Honey & Milk & Species \\
\hline & \multicolumn{4}{|c|}{$(g / l)$} & \multicolumn{3}{|c|}{ (mmol) } & \multicolumn{4}{|c|}{$(\mathrm{ml})$} & Recommended \\
\hline Marine fish ringer & 13.5 & 0.6 & 0.25 & 0.35 & 0.2 & - & - & - & - & - & - & Marine fish \\
\hline Freshwater fish ringer & 7.5 & 0.2 & 0.20 & - & 0.2 & - & - & - & - & - & - & Freshwat. fish \\
\hline Taps & 2.9 & 3.2 & 0.07 & 0.03 & - & 15 & - & - & - & - & - & Tilapia \\
\hline Caps & 2.9 & 3.2 & 0.07 & 0.03 & - & - & 15 & - & - & - & - & Tilapia \\
\hline Milk in ringer & 7.5 & 0.2 & 0.20 & - & 0.2 & - & - & - & - & - & 150 & Tilapia \\
\hline $\mathrm{V}_{2} \mathrm{e}$ & 7.5 & 0.38 & - & - & 2.0 & - & - & 1.0 & 0.2 & - & - & Tilapia \\
\hline$V_{2} f$ & 7.5 & - & - & - & 2.0 & - & - & 1.0 & 0.2 & - & - & Tilapia \\
\hline Honey in ringer & 7.5 & 0.6 & 0.60 & 0.35 & 0.2 & - & - & - & - & 1 & - & $\begin{array}{l}\text { Black porgy, } \\
\text { milkfish }\end{array}$ \\
\hline
\end{tabular}




\section{"CO-CRYOPROTECTANTS"}

Besides cryoprotectants and extenders, some researchers have used a combination of several materials known as "co-cryoprotectants" such as egg yolk, milk, honey, sucrose and glucose to the diluents (Table 3). For instance, Chao et al. (1987) reported that the simplest formulation such as $5 \%$ glucose has generally been the most successful for cryopreservation of tilapia sperm. Further simple or single component diluents such as diluted $0.5 \%$ honey or glucose in Ringer solution were found functional in both laboratory and field for milkfish and black porgy (Chao et al., 1987). Milt diluted with Ringer solution which has been previously combined in methanol is an ideal freezing medium in cryopreserved sperm of several tilapia species including Oreochromis aureus, Oreochromis mossambicus, Oreochromis niloticus, Tilapia zilli, Oreochromis niloticus $x$ Oroechromis aureus hybrid and red tilapia (Oreochromis sp. hybrid) (Chao, 1991).

Egg yolk has been tested as an additive material to extenders and cryoprotectants in many cryopreservation studies. Ciereszko et al. (1993) compared two combined cryoprotectants and found that 8\% DMSO with 10\% egg yolk gave significantly higher fertilization rate than $20 \%$ glycerol with $0.3 \mathrm{M}$ glucose in yellow perch. In addition, Lahnsteiner et al. (1996) pointed out that the addition of egg yolk (7\% and $20 \%)$ and sucrose $(0.5 \%)$ significantly increased the quality of rainbow trout semen in comparison without these additives.

Anuar and Chan (2000) used an extender containing of $0.16 \mathrm{~g}$ calcium chloride, $8 \mathrm{~g}$ sodium chloride, $0.4 \mathrm{~g}$ potassium chloride, $0.2 \mathrm{~g}$ magnesium sulfate, $0.12 \mathrm{~g}$ potassium dihydrogen phosphate, $0.06 \mathrm{~g}$ sodium hydrogen carbonate, $10 \mathrm{~g}$ glucose and $0.15 \mathrm{~g}$ amphicilin for Clarias batrachus spermatozoa, and reported a $68 \%$ of sperm motility at the beginning of storage with survival until day 12 , but a combination of cryoprotectant with $15 \%$ DMSO and $15 \%$ egg yolk maintained sperm motility until day 28 .

In marine fish, a combination of Erdahl-Graham's solution (which contains $0.29 \mathrm{~g}$ of $\mathrm{CaCl}_{2} \cdot \mathrm{H}_{2} \mathrm{O}, 0.4 \mathrm{~g}$ of $\mathrm{MgCl}_{2} .6 \mathrm{H}_{2} \mathrm{O}, 0.5 \mathrm{~g}$ of $\mathrm{Na}_{2} \mathrm{HPO}_{4}, 5.1 \mathrm{~g}$ of $\mathrm{KCl}, 11.7 \mathrm{~g}$ of $\mathrm{NaCl}$., $0.2 \mathrm{~g}$ of citric acid, $20 \mathrm{~g}$ of glucose, $20 \mathrm{~mL}$ at $1.27 \mathrm{~g}$

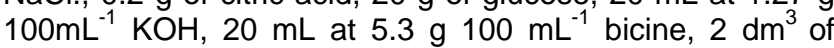
distilled water) and $10 \%$ egg yolk showed positive effects on milt of northern pike (Esox lucius) with increasing fertility rate (Babiak et al., 1995; 1999). Moreover, Piironen (1993) found that the addition of egg yolk in extender for sperm cryopreservation increased the fertilization rates in brown trout (Salmo trutta m. lacustris L), although in Artic charr addition of egg yolk into the diluents decreased the fertilization rate. Similarly, in aspius (Aspius aspius), the presence of egg yolk in the extender significantly decreased cryopreservation success (Babiak et al., 1998).

In addition to the cryoprotectant used, the acceptable dilution ratios of the extenders appear to vary in fish. For example 1 part milt: 1 part extender for the sperm of grey mullet, black porgy, and tilapia; 1:4 for milkfish; and 1:20 for grouper (Chao and Liao, 2001). Tables 1 and 2 show the types of, cryoprotectants, extenders and co-protectants are commonly used respectively.

\section{EFFECT OF CRYOPRESERVATION ON THE SPERM MOTILITY AND FERTILITY}

Motility and fertilization rate of cryopreservation spermatozoa is usually inferior to that of fresh milt. Thus, with frozen semen 15 times more spermatozoa are required for obtaining sufficient fertility in rainbow trout. The lower fertility observed could be due to several factors among them (i) low motility of post-thaw spermatozoa, (ii) the reduced percentage of motile spermatozoa after undergoing freezing and thawing and (iii) low fertility regardless of motility of cryopreserved sperm (Ohta et al., 1995).

In walking catfish (Clarias batrachus) for example, spermatozoa motility decreased from $80 \%$ to $59 \%$, and $38 \%$ after 20,40 , and 120 minutes respectively at a temperature of $10^{\circ} \mathrm{C}$ (Anuar and Chan, 2000). However, Oetome et al. (1996) studied the effect of different cryoprotectants on sperm motility of African catfish, and found that fresh and cryopreserved semen resulted in no significant difference in hatching rate of $82.25 \%$ and $78.9 \%$ for the fresh and cryopreserved sperm respectively.

Furthermore, Ohta et al. (2001) studied the effect of five cryoprotectants namely DMSO, glycerol, methanol, DMA and DMF in Japanese bitterling spermatozoa cryopreservation, they reported that the additional of $10 \%$ DMSO or $\mathrm{N}, \mathrm{N}$-dimethylacetamide (DMA) to the diluents increased the percent motility significantly. The results also showed that $10 \%$ methanol plus $90 \%$ fetal bovine serum as suitable diluents for cryopreservation of Japanese bitterling spermatozoa and those samples should be cooled to $-40^{\circ} \mathrm{C}$ at low freezing rate for effective storage.

Ohta et al. (1995) suggested a correlation between the percentage of fertility and motility of amago salmon (Oncorhynchus masou) after thawing, in that high percentage of motility can increase the fertility. Similar results were found in sea bass and turbot spermatozoa (Dreanno et al., 1998).

Contrarily, Ciereszko et al. (1999) reported no relationship between the motility and sperm fertility in rainbow trout, since $0 \%$ motility had $67.9 \%$ fertilization success. They considered three possible explanations for the phenomenon of cryopreserved sperm for this observation: (i) sperm motility was suppressed by conditions of the sperm analysis chamber, (ii) sperm motility was activated by an egg factor, or (iii) eggs can be fertilized by immotile spermatozoa. The existence of a factor in egg and ovarian fluid that can stimulate sperm motility and could fertilize the egg support the theory that sperm motility was activated by an egg factor. Unfortunately, the mechanism for the stimulation of sperm motility by the egg factor remains unclear. It is suspected that some of the steroid hormones in egg and ovarian have played a role in this phenomenon.

Table 3. The types of co-cryoprotectants used in cryopreservation studies.

\begin{tabular}{llll}
\hline Co-protectants & Combined with & Fish species & References \\
\hline Glucose $5 \%$ & Ringer & Milkfish & Chao et al. (1987); Muchlisin et al. (2004a). \\
Honey $0.5 \%$ & Ringer & Black porgy & Chao et al. (1987) \\
Milk & Ringer-methanol & Tilapias & Chao, (1991) \\
Egg yolk $10 \%$ & DMSO & Yellow perch & Ciereszko et al. (1993) \\
Egg yolk $7 \& 20 \%+$ sucrose $(0.5 \%)$ & - & Rainbow trout & Lahnsteiner et al. (1996) \\
Egg yolk 15\% & DMSO & Walking catfish & Annuar and Chan (2000) \\
Egg yolk $10 \%+$ sucrose $0.6 \mathrm{M}$ & Erdahl-DMSO & Northern pike & Babiak et al. (1999) \\
\hline
\end{tabular}


However, in the most successful cryopreservation, sperm maybe viable and motile after cryopreservation, but their fertility was reduced. Roberts et al. (2000) reported many cryopreserved sperm were immotile, and that the motile sperm rapidly lost their motility and swimming velocity after dilution. They also found the highest fertilization rates obtained were only $20-40 \%$.

\section{CONCLUSIONS}

Cryopreservation has several benefits such as stock protection, a stable supply of sperm for optimal utilization in hatchery production and laboratory experiments, easy stock transportation, improvement in selective breeding and gene transfer. In fact, fish produce a high viscosity of sperm and in some cases only small volume is produced. Extenders and cryoprotectants are important and play a vital role in cryopreservation. Extenders are needed for sperm dilution to produce large volume of diluted sperm while cryoprotectants are also needed to protect the sperm cell from cold and hot shock treatments and prevent cell dehydration during pre-freezing, freezing and post thawed, and its greatly extends the tolerance of spermatozoa to freezing particularly when it is done at slower rate. The optimal cooling rate depends on the nature and concentration of the cryoprotectant that is used. In addition, the suitability of extenders and cryoprotectants differs from one fish to another.

\section{ACKNOWLEDGEMENT}

We gratefully acknowledge Prof. Dr. Roshada Hashim of University Sciences Malaysia for her suggestion to improve this manuscript. Thanks are also due to all members of peer group of Marine Sciences Department Faculty of Sciences, Syiah Kuala University for their helpful during phases of manuscript preparation.

\section{REFERENCES}

Alawi, H., Nuraini, N. Aryani, and S. Hutapea. 1995. Pengembangbiakan Ikan. Pekanbaru: Fakultas Perikanan Univ. Riau.

Anuar, H and S.K. Chan. 2000. Studies on the cryopreservation of keli kayu, Clarias batrachus spermatozoa. In: Proceeding of National fisheries symposium: Challenges to sustainable fisheries development in the next decade (National Agriculture Policy III). Kuala Lumpur: Ministry of Agriculture, Department of Fisheries Malaysia.

Babiak, I., J. Glogowski, M.J. Luezynski, D. Kucharezyk, and M. Luezynski. 1995. Cryopreservation of the milk of the northern pike. Fish Biology 46 (5): 819-828.

Babiak, I., J. Glogowski, R. Kujawa, D. Kucharezyk, and L. Mamearz. 1998. Cryopreservation of sperm of common crap, Cyprinus carpio L. Aquaculture Research 28 (7): 567-571.

Babiak, I., J. Glogowski, M.J. Luezynski, M. Luenzynski, and W. Demianowiez. 1999. The effect of egg yolk, low density lipoprotein methylxanthines and fertilization diluent on cryopreservation efficiency of Northern pike (Esox lucius) spermatozoa. Theriogenology 52: 473-479.

Chao, N.H., W.C. Chao, K.C. Liu, and I.C. Liao. 1987. The properties of tilapia sperm and its cryopreservation. Fish Biology 30: 107-118.

Chao, N.H. 1991. Fish sperm cryopreservation in Taiwan: Technology advancement and extention efforts. International Symposium on Reproductive Biology in Aquaculture. Taipei: Department of Aquaculture, Taiwan Fisheriesv Research Institute.

Chao, N.H. 1996. Cryopreservation of finfish and shellfish sperms. Taiwan Fisheries Research 4(2):157-170.

Chao, N.H and I.C. Liao. 2001. Cryopreservation on finfish and shellfish gametes and embryos. Aquaculture 197: 161-189.

Ciereszko, A., Ramseyer, L., and Dabroski, K. 1993. Crypreservation of yellow perch semen. Progressive Fisheries Culturist American Fisheries Society 55 (4): 261-264.
Ciereszko, A., K. Dabarowski, F. Lin, S.A. Christ, and G.P. Toth. 1999. Effect of extenders and time of storage before freezing on motility and fertilization of cryopreserved Muskellunge spermatozoa. Progressive Fisheries Culturist American Fisheries Society 128: 542-548.

Dreanno, C., M. Suquet, E. Desbruyeres, J. Cosson, H. le Delliou, and R. Billard. 1998. Effect of urine on semen quality in turbot (Scophthalmus maximus). Aquaculture 169: 247-262.

Gallant, R.K., G.F. Richardson and M.A. McNiven. 1993. Comparison of different extender for the cryopreservation of atlantic salmon spermatozoa. Theriogenology 40: 479-486.

Hammerstedt, R.H., J.K. Graham, and J.P. Nolan. 1990. Cryopreservation of mammalian sperm: What we ask them to survive. Andrology 11(3): 7388

Horvath, A., and B. Urbanyi. 2000. The effect of cryoprotectant on the motility and fertilizing capacity of cryopreserved African catfish, Clarias gariepinus sperm. Aquaculture Research 31 (3): 317-324.

Lahnsteiner, F., B. Berger. A. Horvath, T. Weismann, and R. Patzner. 1996. The influence of various cryoprotectants on semen quality of the rainbow trout (Ochorhynchus mykiss) before and after cryopreservation. Journal of Applied Ichthyology 12 (2): 99-106. 21.

Lahnsteiner, F., Berger. B., A. Horvath, B. Urbanyi, and T. Weismann. 2000. Cryopreservation of spermatozoa in cyprinid fishes. Theriogenology 54: 1477-1498.

Linhart, O., R. Billard, and J.P. Proteau. 1993. Cryopreservation of European catfish (Silarus glanis L) spermatozoa. Aquaculture 115: 347-359.

Linhart, O., M. Rodina, and J. Cosson. 2000. Cryopreservation of sperm in common carp Cyprinus carpio: sperm motility and hatching success of embryos. Cryobiology 41: 241-250.

Marian, T. and Z.L. Krasznai. 1987. Cryopreservation of European catfish (Silarus glanis L) sperm. In: K Tiew (ed.). Selection, Hybridization and Genetic Engineering in Aquaculture. Vol I. Hamburg: FAO/EIFAC.

McNiven, M.A., R.K.Gallant, and G.F. Richardson. 1993. Dimethyl-acetamide as a cryopreservation for rainbow trout spermatozoa. Theriogenology 40: $943-948$

Muchlisin Z.A. and Muhammadar. 2002. Long-term cryopreservation of baung spermatozoa, Mystus nemurus: Effect of various cryoprotectants on motility and fertility. Torani 12 (4): 204-210.

Muchlisin Z.A., R. Hashim and A. Chong. 2004a. Preliminary study on the cryopreservation of bagrid catfish spermatozoa : Effect of different extenders and cryoprotectants on the motility after short-term storage. Theriogenology, 62 (1-2): 25-37.

Muchlisin Z.A. 2004b. Preliminary study on spermatozoa cryopreservation and evaluation of dietary protein on gonadal development of bagrid catfish (Mystus nemurus) female Broodstock. Thesis, University Sciences Malaysia, Penang.

Muchlisin Z.A. 2004c. Ultra structure of baung (Mystus nemurus) spermatozoa. Hayati, 9 (2) : 75-77.

Oetome, Z.J., R.N. Nunes, C.K. Kouassi, S. Hem, J.F. Agnese. 1996. Testicular structure, spermatogenesis and sperm cryopreservation in the African clariid catfish. Aquaculture Research 27 (11): 805-813.

Ogier de Baulny, B., C. Labbe, and G. Maisse. 1999. Membrane integrity, mitochondrial activity, ATP content, and motility of the European catfish (Silarus glanis) testicular spermatozoa after freezing with different cryoprotectant. Cryobiology 39: 177-184.

Ohta, H., H. Shimma, and K. Hirose. 1995. Relationship between fertility and motility of cryopreserved spermatozoa of the amago salmon Oncorhynchus masou ishikawae. Fisheries Science 61 (5): 886-887.

Ohta, H., K. Kawamura, T. Unuma, and Y. Takegoshi. 2001. Cryopreservation of the sperm of the Japanese bitterling. Fish Biology 58: 670-681.

Piironen, J. 1993. Cryopreservation of sperm from brown trout (Salmo trutta m. lacustris L) and Arctic charr (Salvelinus alpinus L.) Aquaculture 116 (2-3): 275-285.

Richardson, G.F., L.W. Crim, Z. Yao, and C. Short. 1995. Cryopreservation of yellowtail flouder (Pleuronectes ferrugineus) semen. In: Goetz, F.W and P. Thomas, (eds.). Proc. of the Fifth International Symposium on the Reproductive Physiology of Fish, 2-8 July, 1995, The University of Texas, Austin-Texas. 136p

Richardson, G.F., T.L. Miller, and M.A. McNiven. 2000a. Cryopreservation of rainbow trout semen using dimethyl-acetamide or dimethyl-sulfoxide as cryoprotectant and three size of straw. In: Norberg, B., O.S. Kjesbu, G.L. Taranger, E. Anderson, and S.O. Stefansson (eds.). Proc. of the $6^{\text {th }}$ International Ssymposium on the Rreproductive Pphysiology of Ffish, 49 July 1999, Bergen. Institute of Marine Research and University of Bergen. 443p.

Richardson, G.F., T.L. Miller, and M.A. McNiven. 2000b. Cryopreservation of Arctic charr, Salvelinus alpinus L., semen in various exters and in three sizes of straw. Aquaculture 31: 307-315.

Roberts, R., S. Adams, J. Smith, A. Pugh, A. Janke, S. Buchanan, P. Hessian, and P. Mladenov. 2000. Cryopreservation of abalone (Haliotis iris) sperm. Shellfish Research 19 (1): 530.

Viveiros, A.T.M., N. So, and J. Komen. 2000. Sperm cryopreservation of African catfish, Clarias gariepinus: cryoprotectants, freezing rates and sperm: egg dilution ratio. Theriogenology 54:1395-1408.

Wayman, W.R., R.G. Thomas, and Tiersch. 1996. Cryopreservation of sperm of spotted seatrout (Cynoscion nebulosus). Gulf Research Report 9 (3): 183-188. 